\title{
Developing the Model and Environment for Validation of a Class-8 Truck
}

\author{
Mitchel J. Keil ${ }^{1}$, Upul Attanayake ${ }^{2}$, Pavel Ikonomov ${ }^{1}$ and Richard B. Hathaway ${ }^{3}$ \\ 1. Department of Industrial and Manufacturing Engineering, Western Michigan University, Kalamazoo MI 49008, USA \\ 2. Department of Civil and Construction Engineering, Western Michigan University, Kalamazoo MI 49008, USA \\ 3. Department of Mechanical Engineering, Western Michigan University, Kalamazoo MI 49008, USA
}

\begin{abstract}
Many studies have been conducted by analyzing crash data that included road profile, site conditions, vehicle configurations and weights, driver behavior, etc.. However, limited studies have been conducted evaluating the impact of these factors on crashes and/or rollover through simulations. This is mainly due to lack of availability of verified full vehicle flexible-body models. The verification process is costly as it requires instrumentation of a heavy vehicle, scanning of road surfaces, and collection of data by running the vehicle over different road conditions, performing various maneuvering, etc. This paper presents the reverse engineering process of a class- 8 truck and validation of a full flexible-body simulation model of a Wabash 53-foot trailer against the strain data recoded from proving ground testing of an instrumented truck. Simulation results show that, with the exception of the noise from the strain gage data from instrumented test run at $30 \mathrm{mph}$, there is a good agreement in periodicity and relative amplitude with the ADAMS model. A comparison of strain data from the flex-body model and the instrumented truck shows that the modeling and verification approach presented in this paper can be confidently used to validate the full flexible-body models developed for specific analyses.
\end{abstract}

Key words: ADAMS simulation, class-8 truck, flexible-body, instrumentation, road profile.

\section{Introduction}

According to the 2008 data published by the National Highway Traffic Safety Administration, in the US alone, 380,000 large trucks that weigh more than 10,000 pounds were involved in crashes. Out of the 380,000 crashes, 4,066 were fatal crashes while 66,000 were injury crashes. As a result of these crashes, 4,229 were killed and 90,000 were injured [1]. It has been noted that the fatality rate for occupants of large trucks in single-vehicle crashes with a rollover is over 64 percent [2]. Vehicle rollover causes immense safety, economic, and environmental problems [3]. The majority of the studies have been conducted by analyzing crash data that included road profile, site conditions, vehicle configurations and weights, driver behavior, etc. [3]. However, limited studies have been

Corresponding author: Mitchel J. Keil, PhD, P.E., research fields: vehicle simulation, automatic routing of flexible elements, machine design and reverse engineering. E-mail: mitchel.keil@wmich.edu. conducted evaluating the impact of these factors on crashes and/or rollover through simulations [11]. Full flexible body simulation is vital to understand the significance of these factors on heavy vehicle crashes and/or rollover and to develop accident prevention techniques. Though the current technology is adequately developed to perform the full flexible body simulations, the progress is limited due to lack of verified models. The verification process is costly as it requires instrumentation of a heavy vehicle, scanning of road surfaces, and collecting data by running the vehicle over different road conditions, performing various maneuvering, etc..

The main objective of this paper is to discuss instrumentation, road surface scanning, the reverse engineering process of a class- 8 truck, and validation of the full flexible-body model of a Wabash 53-foot trailer against the strain data recoded from proving ground testing in ADAMS environment simulating one out of six testing scenarios. Scope of the paper is 
limited to instrumentation, road surface scanning, reverse engineering, challenges or technology limitations, and verification of a flexible-body model using limited test data. The paper does not necessarily address a model development process for any specific analysis such as crashworthiness.

\section{Instrumentation and Data Analysis}

\subsection{Instrumentation}

A Peterbilt 379 truck and a Wabash 53-foot trailer were instrumented. One Oxford RT2500, inertial measurement system, was secured to the floor in the cab on the right hand side of the driver's seat. An Oxford RT3100, inertial measurement system, was mounted to a stand and secured to the floor of the trailer. Both inertial systems were used to collect vehicle dynamics data from each independent body for yaw, pitch and roll angles, rates and acceleration as well as GPS (global position system) location. The SoMat eDAQ placed in the cab is connected to all sensors. The information offers overall performance to confirm and guide the development of the multi body flex models of the truck and trailer in a computer environment, MSC.ADAMS. It is important to document the behavior of vehicle components at the same time to understand the interaction of each component and the behavior of the entire vehicle in order to validate the flex-body model developed in a computer environment for further analysis. Data from air bag pressure sensors, in both the rear truck suspension and the trailer suspension, were recorded. Linear displacement sensors were placed in parallel positions of the front and rear truck shocks as well as the trailer shocks. A combination of rosettes was placed on the sidewall of the truck frame and in the same axis with single strain gages on the top and bottom flanges. The rosettes were used for capturing strain from torsion while the single gages on the flanges capture strain from vertical bending. Two sets of this combination were used on the left and right front section of the frame as well as two more sets at the left and right mid-point of the rails, just behind the cab. Fig. 1 depicts the locations of the sensors installed on the truck and trailer. A list of sensors used in this project are listed below:

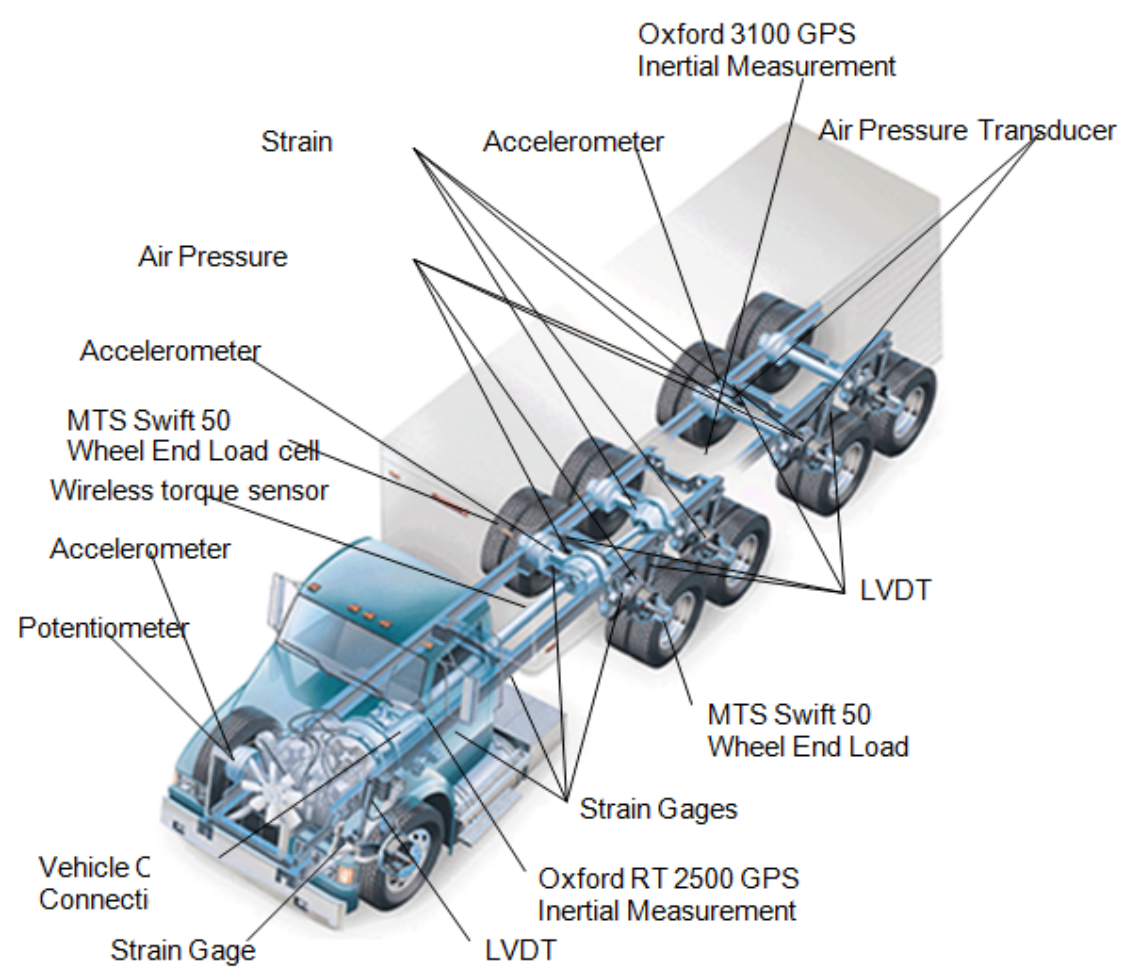

Fig. 1 Instrumentation layout. 
- 28 single strain gages;

- 5 rosette strain gages;

- 4 air pressure transducers;

- 6 linear displacement sensors;

- 3 accelerometers;

- 1 rotory potentiometer;

- 1 wireless driveline torque sensor;

- 2 Oxford inertial measurement systems;

- 4 micro camera system;

- Tractor CAN bus data.

\subsection{Data Analysis and Challenges}

Data collection over several special events at the Bosch proving ground was performed, in addition to simpler events like straight line braking (confirm weight transfer of the models), high speed oval lane change (transient lateral load transfer of the models), constant radius (steady state lateral loading of the model) and the chuck hole (single event impact load transfer). The list of test scenarios is provided below:

- 30 mph double lane change;

- 33 mph braking;

- 65 mph braking;

- 65 mph double lane change;

- Big oval at $32 \mathrm{mph}$;

- Big oval at 62.

\section{Road Events Scanning}

The proving ground testing track has events varying from 10.5 feet wide to 17.5 feet wide with a very

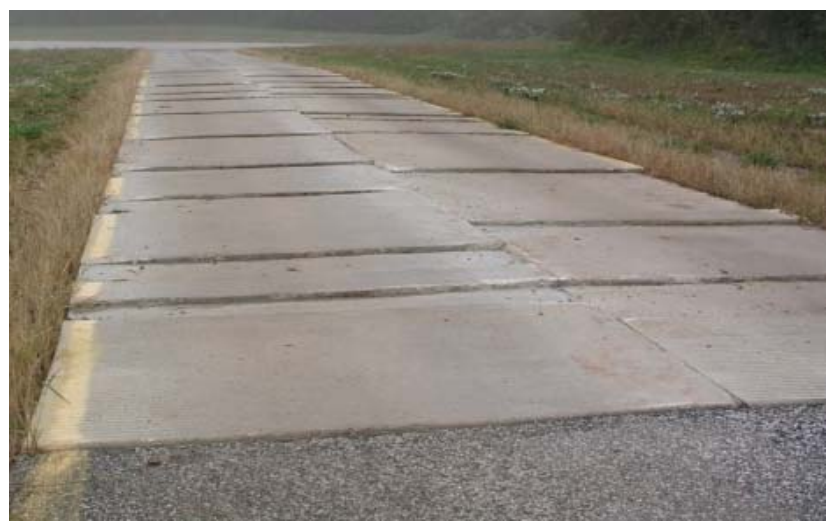

(a) Staggered bumps

Fig. 2 Example events of the testing track. uneven surface made for testing trucks and cars. An event is the section of the track that is built for some specific purpose. For example, frame twist bump is an event which is used to test the vehicle for frame deformations under torsion. Fig. 2 shows two events at a testing track. The section of the track in Fig. 2a is called the staggered bumps and the one in Fig. $2 \mathrm{~b}$ is called the cobble stones. These two are just a few of many events of the track. Each event of the track has varied height, depth and width.

The testing track is not all flat surfaces that can be measured easily with conventional tools. For this reason, a special scanning trailer was designed to allow movement of the scanners smoothly over the testing track and record accurate and precise data while scanning. The trailer built was light, yet rigid, easy to assemble and disassemble for transportation. Wheel spacing of the trailer was made adjustable from 10.5 feet to 17.5 feet in the interval of 6 inches to facilitate scanning of various events of the testing track.

Two scanners were fixed rigidly on the trailer. The first scanner was elevated several feet above the ground and placed on a platform supported by a triangular mounted structure on the trailer, so that even a 100 degree scan can cover the entire width of the event. The height of the scanner from the ground was also made adjustable. The second scanner was fixed rigidly to the frame of the trailer.

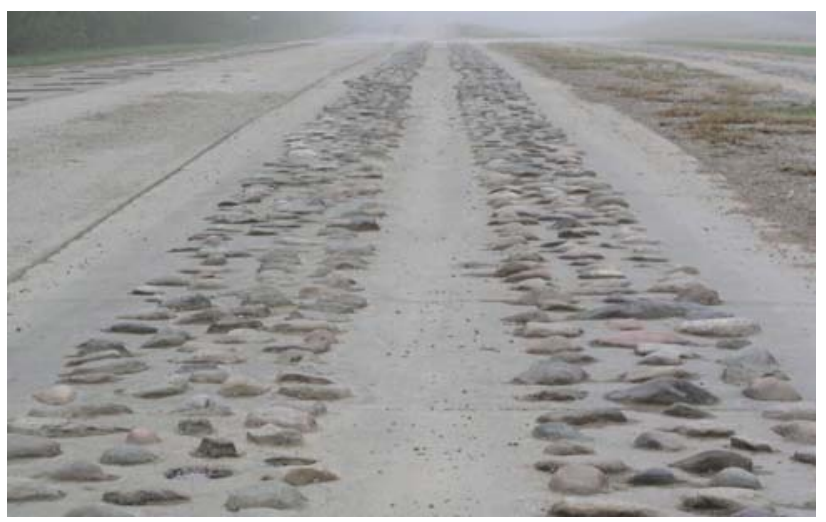

(b) Cobble stones 
The trailer wheel movement was controlled using self-guiding rail guides. The rail guides were placed on the flat surface on both sides of the road profile which allowed steady motion of the trailer over the reference plane defined by the rail guide system. The guide rails were very light and could be carried and adjusted by a single person, the length varied from 20 to 60 feet and could be easily extended for longer events.

The trailer has a special box to accommodate and carry a car battery, a power inverter, two laptops and few tools for assembling/disassembling and those needed during the measuring process. Fig. 3 shows the trailer with the scanners and the profiles of the scan lines. Fig. 4 shows the picture of the trailer with scanners and imaginary scan lines.

\section{Scanning Process and Surface Construction}

Both scans were started simultaneously. The scanning frequency was $1 \mathrm{~Hz}$. The speed of the trailer is kept constant. The pitch of successive scans depends on the trailer speed. One scanner scanned and recorded the data in the $\mathrm{XZ}$ plane along the width of the trailer while the other scanner scanned and recorded the data in the $\mathrm{YZ}$ plane.

Each of the scanners on the trailer gives the 2D information about the road profile, which when combined together using the scan matching algorithms gives the $3 \mathrm{D}$ data. This $3 \mathrm{D}$ data or the point cloud data set was filtered to remove the outliers. Later the data

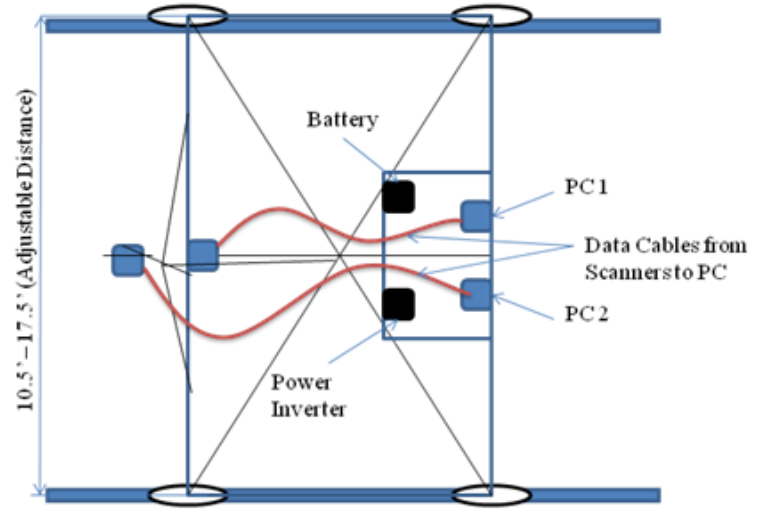

(a) Plan view was processed to reduce the noise. Refined point cloud data was then used to create the mesh surface. Feature extraction gave a high quality representation of the road profile. A schematic flowchart shows how the laser scanner measuring system operates (Fig. 5). The surface model is then exported/saved as stereo-lithography (.stl) 3D data format to use in MSC.ADAMS simulation software. Detailed discussion on road profile scanning and surface generation is given in Ref. [11].

\section{Flex-Body Modeling and Simulation}

\subsection{Finite Element Modeling and Modal Neutral Files}

The process of developing a flexible body model of the class 8 truck involved several steps. It began with reverse engineering the tractor and trailer into solid model components. Reverse engineering of the trailer was accomplished through measurements and photographs being transferred to solid model geometry. This was augmented with some sparse digital scan data.

Once the geometry was complete, it was further processed in Refs. [13] by generating finite element meshes that were converted into modal neutral files. The components that comprise the main structural system mass and stiffness of class-8 truck are: trailer box, frame, slider and axle; tractor frame, fifth wheel and axles. The complete trailer box and frame model consist of 89,540 nodes and 85,237 shell elements (S4

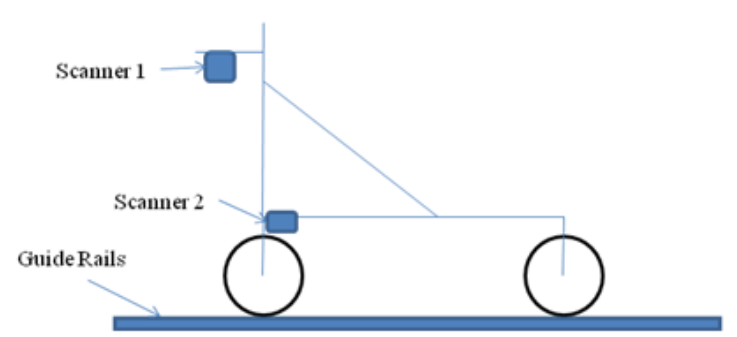

(b) Elevation

Fig. 3 Plan and elevation views of the trailer with scanners and other accessories. 


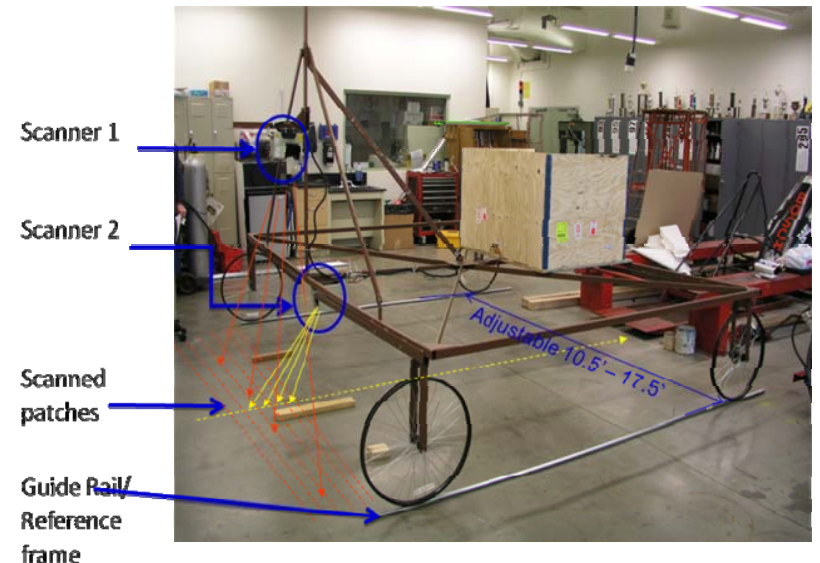

frame

Fig. 4 Picture of the trailer and imaginary lines of scanned path.

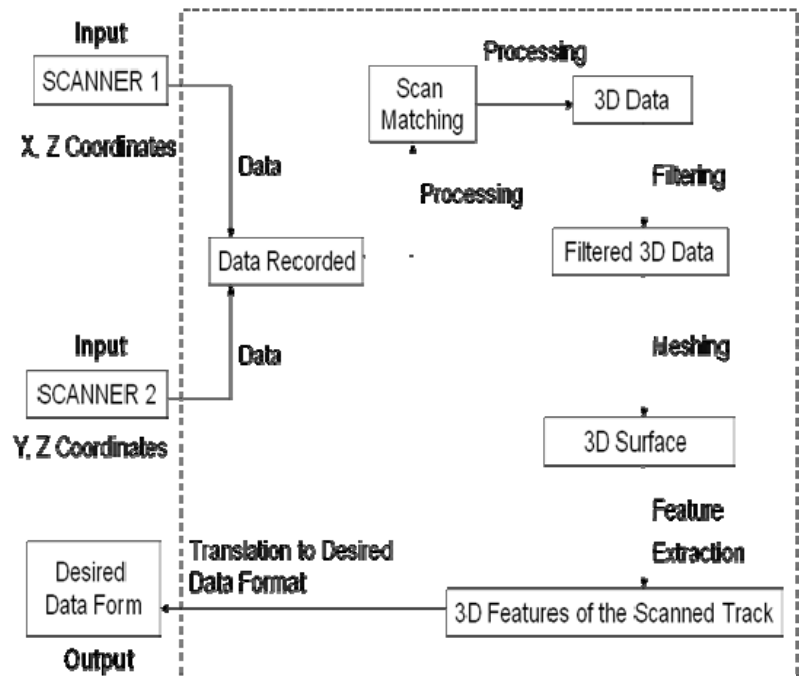

Fig. 5 Schematic diagram of the road scanning system.

and S3) (Fig. 6). Natural frequency analysis, which provides mode shapes coupled to each mode of free vibration, was performed and the mode shapes were utilized to verify the connections between individual components.

FE (finite element) models of slider box, axel arms, and axles consist of shell elements (S3 and S4) as well as solid brick elements (C3D8). Once the connections were verified between components, master nodes were assigned to the required positions referring digital images and the original CAD files. Rigid beam elements in ABAQUS were used to develop the master nodes (Figs. 7-9). Similar procedure was followed for generating FE models of tractor frame, fifth-wheel, and the axles.
Flexible body dynamic simulation using MSC.ADAMS require modal neutral files of these structural components or their assemblies. The level of accuracy depends on the finite element model refinements and the level of actual geometric data in the model. Hence, refined finite element models were developed closely representing the actual geometry but within the limits of computer hardware capacity to analyze such detailed models. Substructures were developed by assembling components and assigning master nodes. ABAQUS generates a list of fixed-interface vibration modes. The ABAQUS interface for MSC.ADAMS combines these fixed-interface modes with the static constraint modes to compute an equivalent modal basis to be used by ADAMS/Flex. These frequencies are written to the screen when executing the ABAQUS interface for MSC.ADAMS. Once the modal neutral files were imported to ADAMS/Flex, a list of frequencies were obtained and compared with the frequencies displayed on the screen during modal neutral file conversion using ABAQUS interface for MSC.ADAMS. The frequency matching verifies an accurate transfer of models between ABAQUS and MSC.ADAMS. Following this procedure, modal neutral files of the assemblies were developed, imported to MSC.ADAMS, and verified to be accurate in the transfer of models between ABAQUS and MSC.ADAMS. After the files were imported and assembled in ADAMS to generate flexible bodies, the analysis was performed by incorporating various tire models (e.g., FTire, Fiala and Pacejka) and road profiles.

5.2 Flex-Body (ADAMS) Simulation, Challenges, and Model Verification

Models of the class 8 truck were developed in ADAMS using flexible elements. This approach was followed because of discussions with analysts from DANA Corporation where it was found that rigid structures often gave erroneous results. However, 
modeling the truck in ADAMS Car proved to be problematic. The initial problem was that the software required several patches in order to run 18 wheeled vehicles. Once the patches were successfully installed, work on the truck model began by using templates for flexible and rigid tractors and trailers.

Even with the patches it took several weeks to get the template to work since they are incomplete. A rigid tractor-trailer assembly was finally made functional from one template. This was followed by a flexible tractor. The flexible tractor-trailer template was never made functional.

The solid modeling efforts on the trailer assembly far outpaced the tractor. Thus, the model of the flexible trailer was developed first. The original plan was to incorporate components into the flexible trailer template, but as noted, the flexible tractor-trailer template was never made functional. The rigid trailer template was therefore used to develop the flexible model of the trailer.

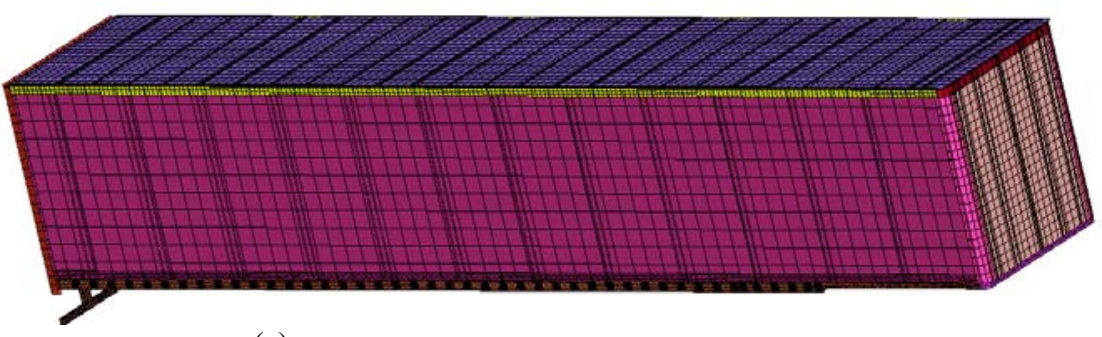

(a)

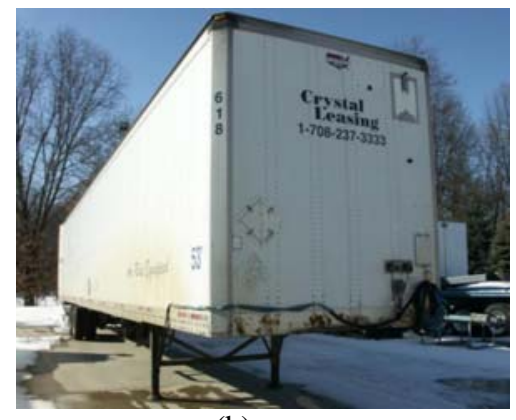

(b)

Fig. 6 Complete trailer box and frame FE model.
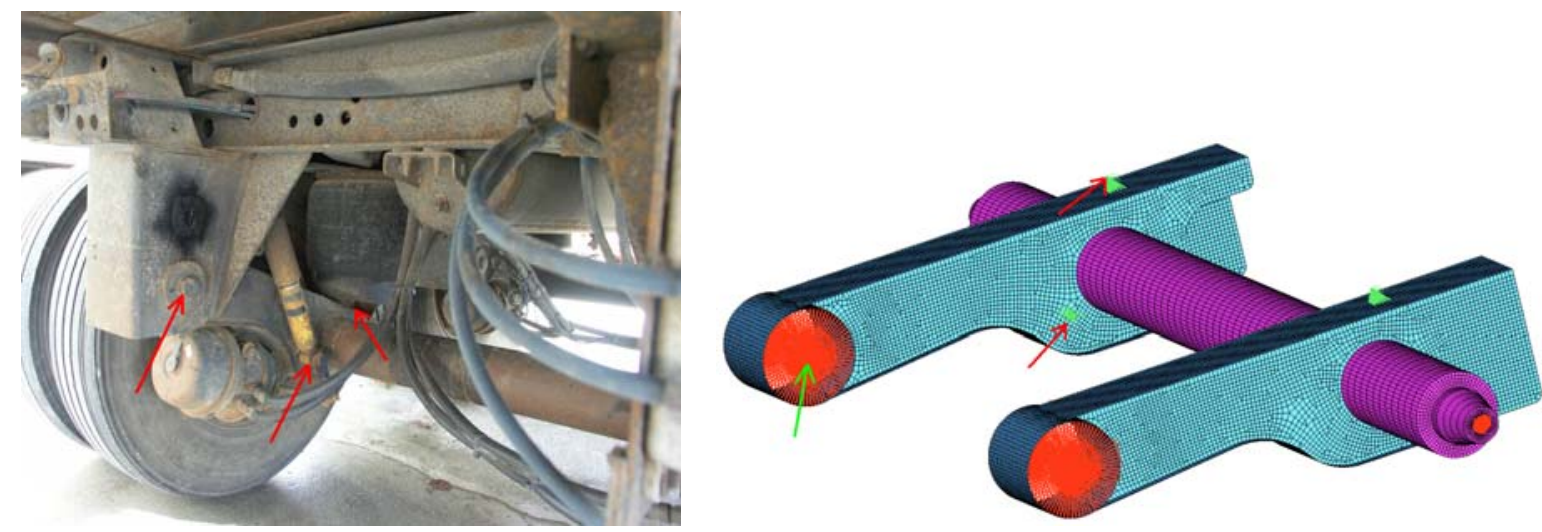

Fig. 7 Connecting points between axle-bushing plate, axle-damper, and axle air suspension.
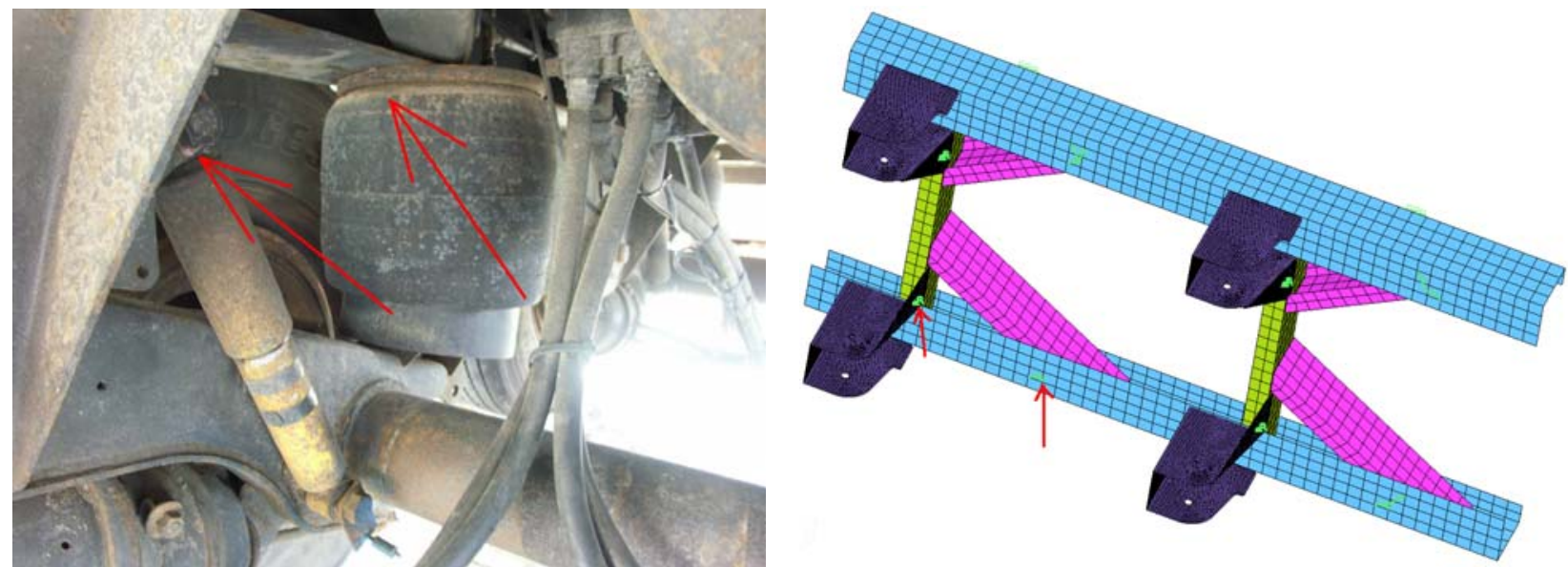

Fig. 8 Connecting points on slider frame. 

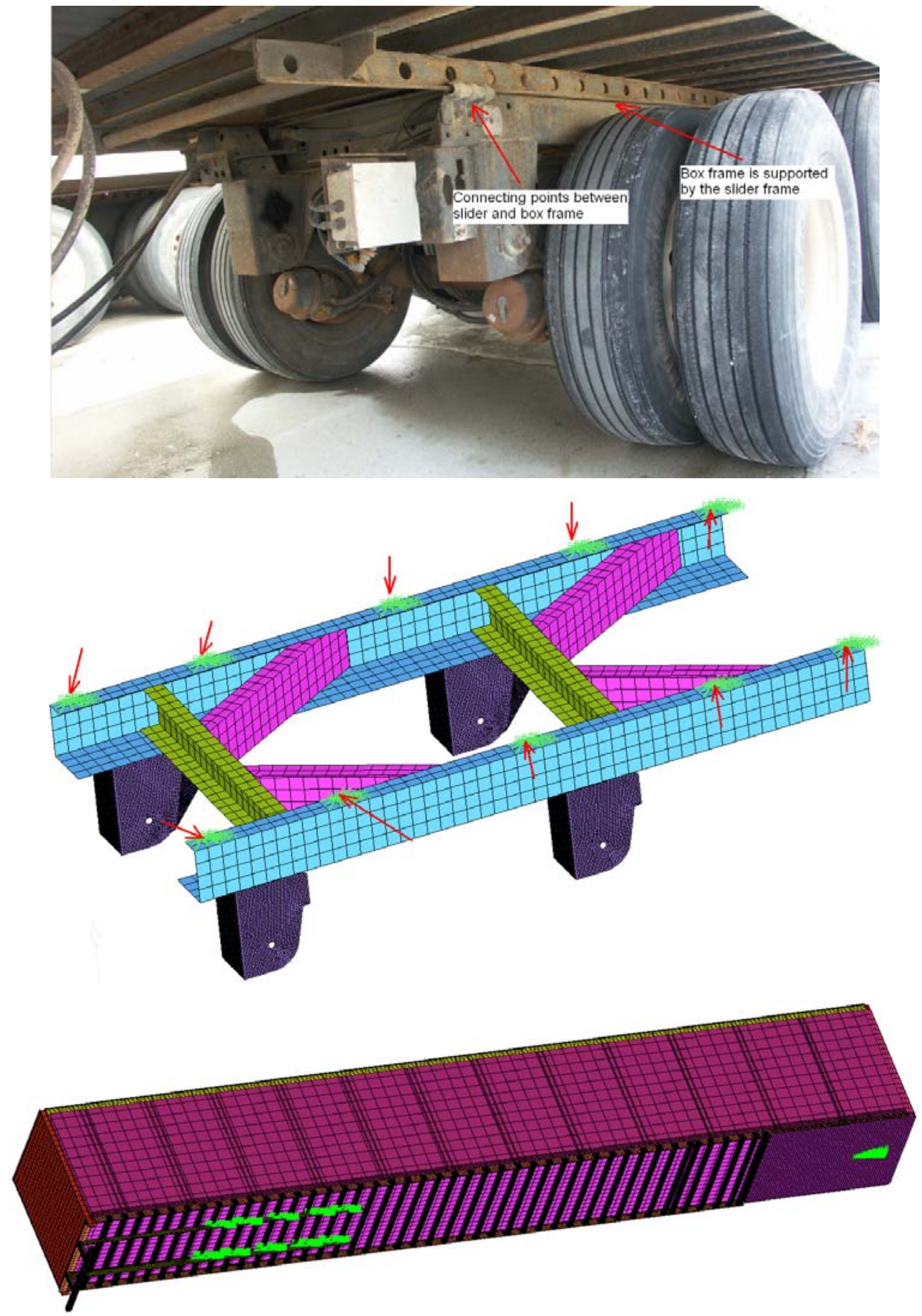

Fig. 9 Master nodes on the slider, the trailer frame, and at the king-pin.

Several software tools were used on the project, but ADAMS played a significant role as the project moved forward. For example, Fig. 10 shows a full flexible-body model of a trailer with a rigid tractor that was developed using modal neutral files generated from ABAQUS.
The power of ADAMS modeling can be seen in Fig. 11 where one node on the model has been selected to study the strain history during a lane change maneuver.

The strain history of this node was then compared to data taken from a strain gage mounted on the trailer axle at a similar location (Fig. 12). The strain gage data 
in Fig. 12 has been highlighted in a bounding box to correspond to the ADAMS output. With the exception of the noise from the strain gage, one can see the there is good agreement in relative amplitude and periodicity with the ADAMS model. Comparison of strain data from flex-body model and instrumented truck shows that the flexible body model is adequately refined for further analysis.

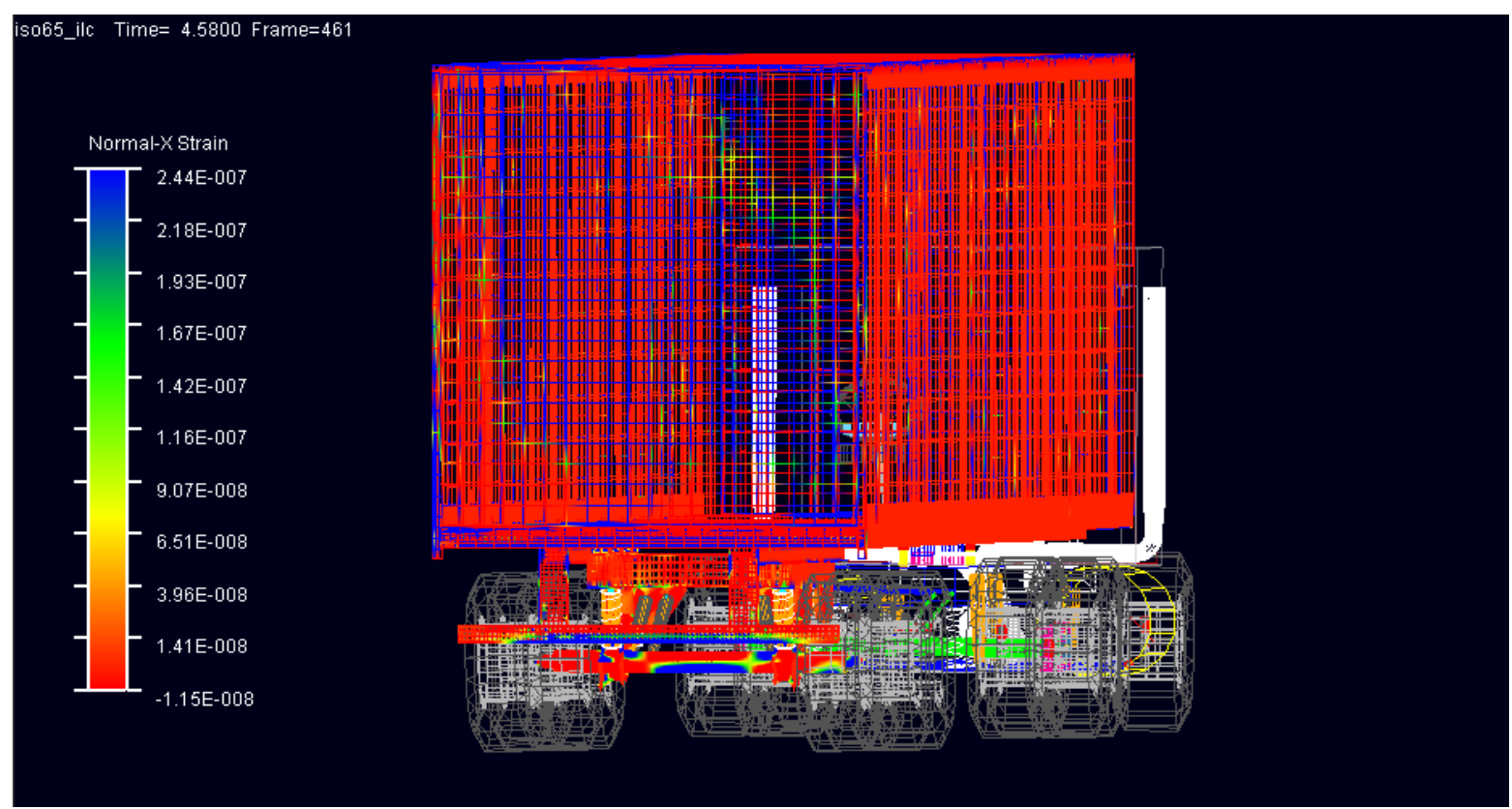

Fig. 10 Full flexible-body model of a trailer with a rigid tractor.

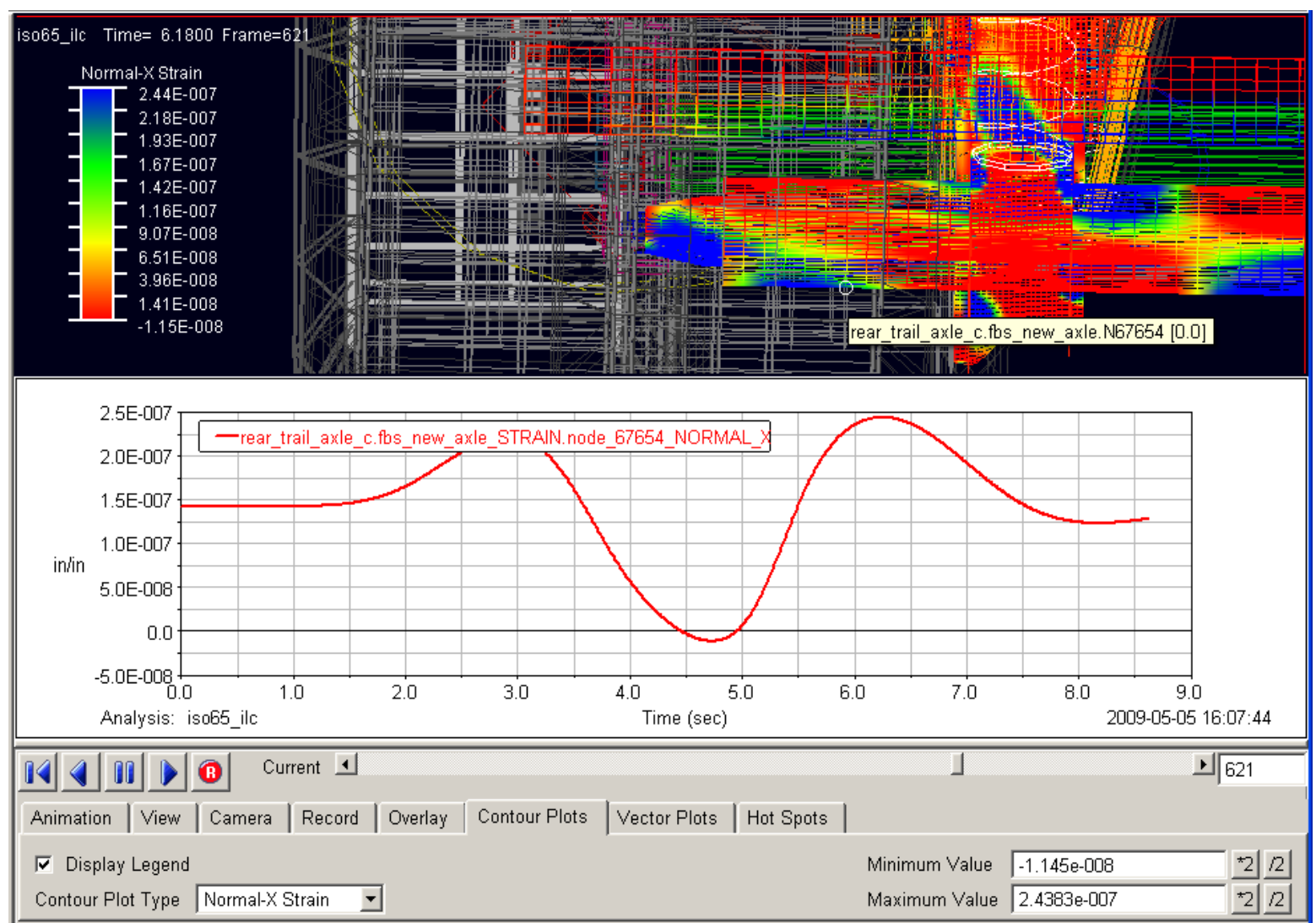

Fig. 11 A time history of strain on a node in the model. 


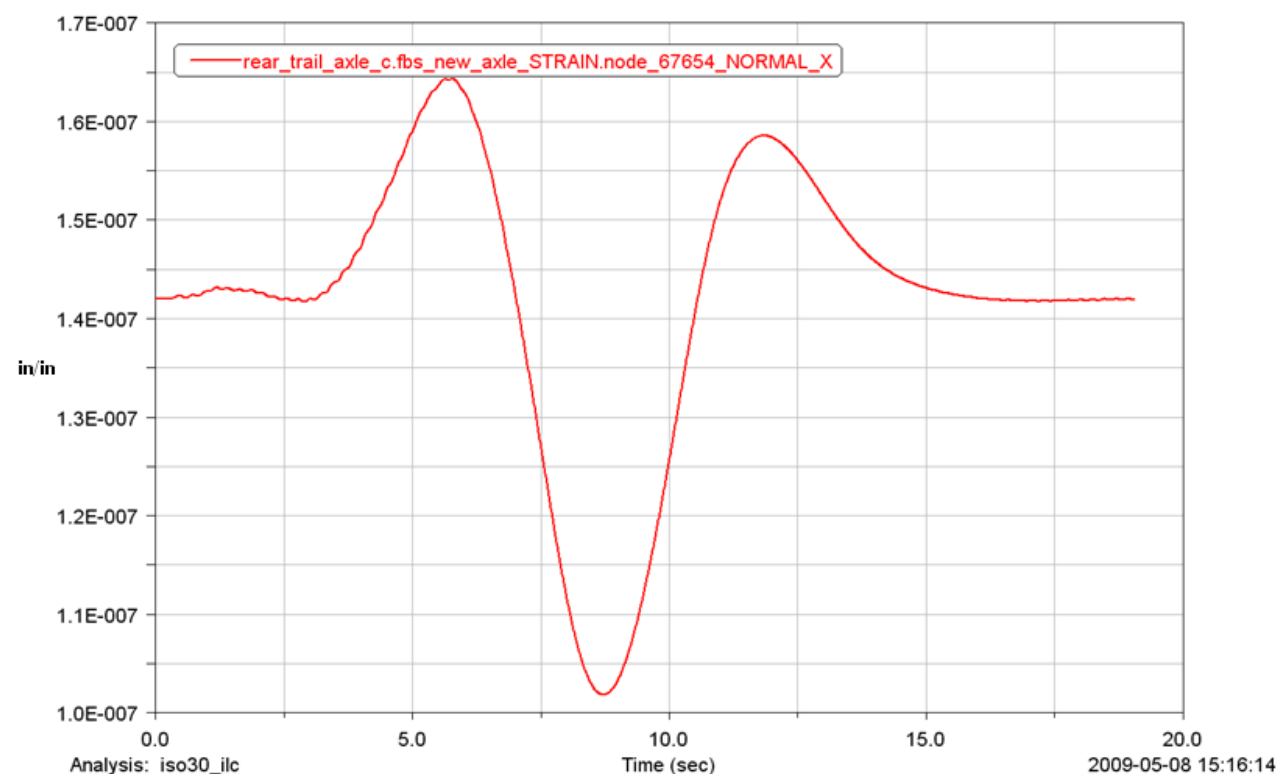

(a) Strain data from ADAMS run at $30 \mathrm{mph}$

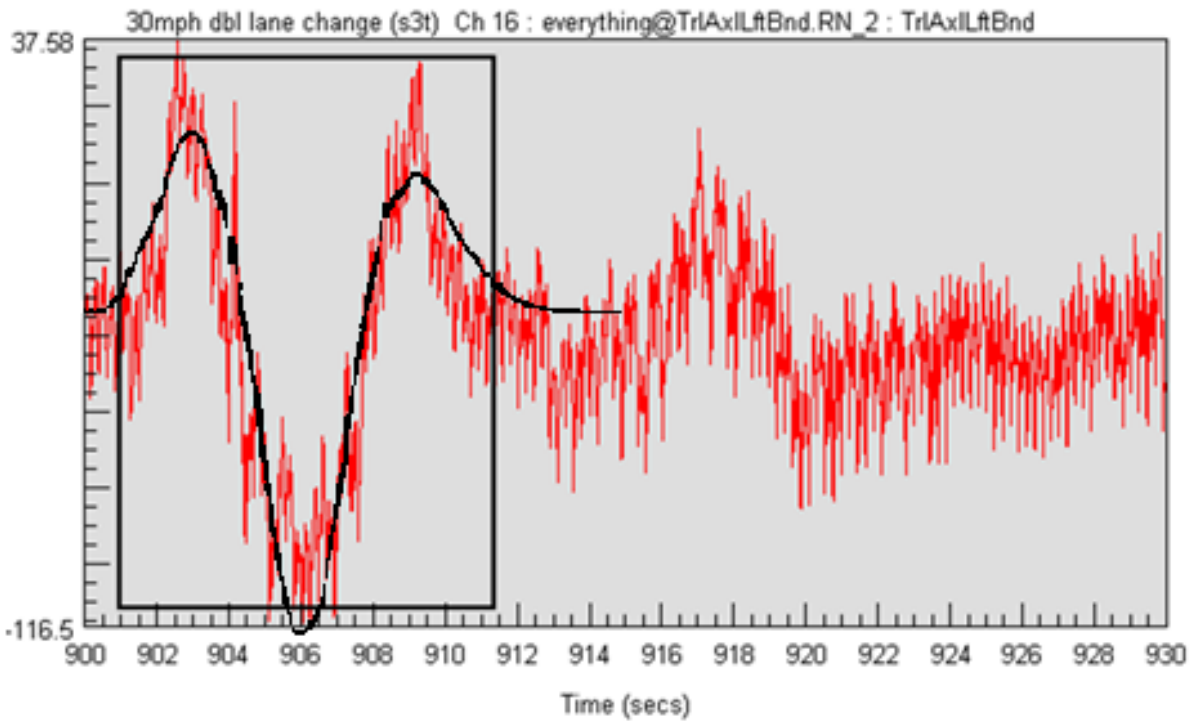

(b) Strain data from instrumented test run at $30 \mathrm{mph}$ with ADAMS run overlay

Fig. 12 ADAMS output compared to strain gage data.

\section{Summary and Conclusions}

The study presented here included the reverse engineering process of a class- 8 truck and validation of the flexible-body simulation model of Wabash 53-foot trailer against the strain data recoded from proving ground tests. Simulation results show that, with the exception of the noise from the strain gage data from instrumented test run at $30 \mathrm{mph}$, there is a good agreement in periodicity and relative amplitude with the ADAMS model. Agreement with periodicity represents accurate distribution of mass and stiffness in the model. It is unrealistic to match the actual amplitude unless the model is tweaked through a parametric study that requires significant amount of time and effort due to complexity of the model. An additional objective of this article is to disseminate the information on availability of complete CAD model of the truck, instrumented truck test data for six different maneuvers, and road surface scan data. In future, full 
flexible-body models of semi-trailer can be developed targeting specific analyses and be verified using available test data to conduct rollover or crashworthiness to understand impact of various parameters for developing safe trucks.

\section{Acknowledgments}

This material is based upon work for the CAViDS (Center for Advanced Vehicle Design and Simulation) at Western Michigan University. The work is supported by the U.S. Army TACOM Life Cycle Command under Contract No. W56HZV-08-C-0236, through a subcontract with Mississippi State University and was performed for the SimBRS (Simulation Based Reliability and Safety) research program.

\section{References}

[1] NHTSA (National Highway Traffic Safety Administration), Traffic Safety Facts-2008 Data, National Center for Statistics and Analysis, NHTSA, Washington DC, 2008.

[2] NHTSA (National Highway Traffic Safety Administration), An Analysis of Fatal Large Truck Crashes, U.S. Department of Transportation, NHTSA, DOT HS 809 569, 2003, p. 30.

[3] A. J. McKnight and G. T. Bahouth, Analysis of large truck rollover crashes, in: Annals of Advances in Automotive Medicine - 52nd Annual Scientific Conference, Vol. 52, 2008, pp. 281-288.

[4] E. R. Braver, P. L. Zador, D. Thum, E. L. Mitter, H. M. Baum and F. J. Vilardo, Tractor-trailer crashes in Indiana: A case-control study of the role of truck configuration, Accident Analysis and Prevention 29 (1) (1997) 79-96.
[5] M. Gothié, Heavy vehicle accident factors, in: 9th International Symposium on Heavy Vehicle Weights and Dimensions, Pennsylvania State University, PA, USA, June 18-22, 2006.

[6] J. D. Pont, Heavy truck safety in Tasmania, in: 9th International Symposium on Heavy Vehicle Weights and Dimensions, Pennsylvania State University, PA, USA, June 18-22, 2006.

[7] J. C. Cheng and J. Le, Challenge faced by truck frontal crash analysis, in: Proceedings of the 1994 ASME International Computers in Engineering Conference and Exhibition, ASME, New York, NY, 1994, pp. 607-613.

[8] Y. Liu, Development and evaluation of a finite element truck chassis crash model, International Journal of Crashworthiness 15 (1) (2010) 107-113.

[9] C. K. Thorbole and S. A. Batzer, Occupant protection via frontal crash testing analysis, in: Proceedings of the 2008 ASME International Computers in Engineering Conference and Exhibition, ASME, New York, NY, 2009, pp. 101-107.

[10] P. Douglas, A. Michael, N. Susan, F. Oscar, K. Helmut, L. C. Tim, U. Attanayake, R. Hathaway and M. Keil, Heavy Truck Rollover Characterization (Phase B), National Transportation Research Center, Inc. University Transportation Center, Knoxville, TN, 2009.

[11] W. Liou, U. Attanayake, R. Hathaway, P. Ikonomov, M. Keil, D. Kujawski and L. Lamberson etc., Simulation-Based Heavy-Duty Truck Structural Reliability Analysis, Track Pin Bushing Fatigue, and HMMWV Underbody Scanning, TARDEC (Tank Automotive Research Development and Engineering Center), Warren, MI, 2008.

[12] HyperMesh User Manual, version 11, Altair Engineering, Inc., 2010.

[13] ABAQUS user manual, version 6.10, Dassault Systemes, 2010. 